\title{
S.] КОНСУПЬТИРОВАНИЕ
}

Камзин Н.Л.

\section{ПРЕДПРИНИМАТЕЛЬСКИЙ РИСК: НЕОБХОДИМОСТЬ ЗАЩИТЫ, СУЩНОСТЬ}

Аннотация: В статье определяется риск как понятие. Рассматривается внутренняя и внешняя сущуноть предпринимательского риска, необходимость его защитьл. Анализируется предпринимательская прибыль как результат инновационной деятельности и источник управления риском. Рассматривается механизм движения инновационной идеи предпринимателя в сравнении с перемещением актуальной информацией.

Ключевые слова: Юриспруденция, сущуность, предпринимательство, риск, комбинация, фактор, новация, потребность, должник, прибыль.

Review: The article concerns entrepreneurial risk as a term. The author analyzes inner and outer nature of entrepreneurial risk and the necessity of protection, as well as entrepreneurial profit as a result of innovative activity and the source for the risk management. The author evaluates the mechanism of introduction (movement) of an innovative idea of an entrepreneur as compared with the transfer of topical information.

Keywords: jurisprudence, nature, entrepreneurial, risk, combination, factor, innovation, need, debtor, profit.

\section{Введение}

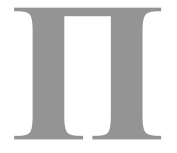

редприниматель как активный субъект экономической сферы общества и предпринимательство как фактор производства общественных благ социально значимые явления. Для любой активности необходим аспект стабильности или соразмерность потенциального урона при неблагоприятном развитии ситуации и вознаграждения от положительного результата. Предприниматель имеет дело с крайней моделью данного баланса.
В настоящее время государство декларирует необходимость поддержки малого и среднего предпринимательства, ожидая их экономической активности и доходов в виде налогообложения их деятельности и операционного доход от проводимых ими расчетов по обязательствам. Для внедрения своей идеи в жизнь предприниматель определяет для себя целесообразность данного предприятия и оценивает всевозможные риски. Так как его «новая комбинация» представляет неопределенность, которую способна развеять лишь практика. Таким 
образом актуальность данной статьи не вызывает сомнений.

Объектом исследования являются теоретические аспекты предпринимательских отношений.

Предмет исследования представлен сущностью предпринимательского риска, необходимостью и возможностью его защиты или сглаживания в современных реалиях.

Цель работы состоит в том, чтобы охарактеризовать сущность предпринимательского риска, обосновать необходимость его защиты.

Для достижения цели требуется решение следующих задач:

- $\quad$ определить проявление сущности предпринимательского риска в окружающем мире, его внешнюю сущность;

- определить существо предпринимательского риска;

- обосновать необходимость и целесообразность защиты предпринимательского риска.

Предпринимательский риск это обозначение некоторого явления действительности, а любое явление определяется в сознании исследователя посредством осознания его сущности. Сущность двуедина, ввиду наличия у каждого явления внутренней и внешней сущности. Внутренняя сущность объемлет потенцию, возможности, витальные характеристики явления. Внешнее - это обнаружение вовне внутреннего, это то, что характеризует со стороны его связи с предметами другой системы отношений ${ }^{1}$. Внешняя сущность - это проявление внутренней сущности в действительности. Прежде всего, мы имеем дело с внешней сущностью, а выявив закономерности, подобия в нашем сознании проявляется внутренняя сущность, которая в явлении стабильна. Внешняя же динамична

${ }^{1}$ Спиркин А.Г. Философия.- М.: Гардарики.-2006.C. 280 . и проявляется в разных «амплуа» в зависимости от окружающей действительности. При постановке вопроса о сущности какоголибо явления подразумевается определение внутренней сущности через призму внешней сущности. Актуальность данного вопроса неумолима ввиду динамичности внешнего мира и различного проявления в нем сущности явлений, подобно актеру, играющему разные роли в постановках в течение жизни. От компетентности исследователя зависит выявление сущности исследуемого явления или наречение данного явления как новоявленного, оригинального. В динамике оригинальным и новоявленным может быть лишь его проявление, но никак не внутренняя сущность, составляющая базис.

\section{Внешняя сущность предпринимательского риска}

По теории Й. А. Шумпетера проявлением предпринимательства является новаторство, генерация «neue Kombinationen»» ${ }^{2}$ факторов производства. Предпринимательство наряду с капиталом является катализатором «комбинаций» способствует их воплощению и функционированию. При организации предпринимательской деятельности, предприниматель после зарождения идеи осуществляет, кроме прочего, материальную подготовку ее реализации. Для этого, прежде всего, использует капитал, свой либо заимствованный. Нельзя стать предпринимателем, не став предварительно должником. Он становится должником в силу внутренней необходимости, присущей процессу развития ${ }^{3}$. Под развитием

\footnotetext{
${ }^{2}$ Schumpeter J.A. Theorie der wirtschaftlichen Entwicklung. Siebentes Kapitel. Das Gesamtbild der Volkswirtschaft. Leipzig.: Duncker \& Humblot. 1912. P. 4.

${ }^{3}$ Шумпетер Й. А. Теория экономического развития. М.: Директмедиа Паблишинг. 2008. С. 211.
} 


\section{Тренды и управление - №3(3) • 2013}

полагается поступательное движение вперед. Побудить к этому может либо мотивация собственной воли, либо внешняя стимуляция, обязанность, долг. Должник обременен обязанностью в отношении кредитора, правомочие кредитора возникло в результате ссуды должнику собственного капитала. Должник возвращает кредитору капитал в большем размере, нежели получил от него ранее. «Берет чужое, а отдает свое» для того чтобы отдать он может либо реализовать свою идею и получить прибыль, либо отдать свою собственность. Рациональным будет осуществление предпринимательской инициативы, нежели ухудшение своего материального положения, потому долг стимулирует осуществление экономических отношений, их развитие.

В случае заблуждения предпринимателя касательно его новации, используемый капитал и его личный потенциал являются той совокупностью, которая поглощается в результате предпринимательской инициативы. Но эта же совокупность может стать источником предпринимательской прибыли, из которой потенциально возможно формирование фондов покупательной силы ${ }^{1}$ для реализации, на данный момент, зарождающихся и потенциально уместных в будущих реалиях «новых комбинаций».

Современный предприниматель и бизнесмен слились воедино, предприниматель, остающийся таковым на протяжении десятилетий, встречается также редко, как и коммерсант, который никогда в жизни не бывал хоть немного предпринимателем ${ }^{2}$. В общественном сознании данные понятия идентичны, однако именно по части рисков

\footnotetext{
${ }^{1}$ Шумпетер Й. А. Теория экономического развития. М.: Директмедиа Паблишинг. 2008. С. 236

${ }^{2}$ Шумпетер Й.А. Теория экономического развития. М.: Директмедиа Паблишинг. 2008. С. 174.
}

они диаметрально противоположны. То или иное лицо в принципе является предпринимателем, только если оно «осуществляет новую комбинацию» - оно перестает быть таковым, когда учрежденное им «дело» начнет дальше функционировать в рамках кругооборота ${ }^{3}$. Бизнесмен в результате практики осуществления внедренной в качестве предпринимателя комбинации постепенно выявляет все «слабые места» ее осуществления и минимизирует риски. Это происходит путем совершенствования механизма. Предприниматель со своей новацией осуществляет только теоретическое выявление слабых участков, используя свои знания, и прошлый опыт моделирует развитие стечения обстоятельств и осуществление значимых действий, своих собственных и окружающих. Потому бизнесмен рационализирует свою деятельность при минимизации рисков, а предприниматель посредством ratio 4 анализирует способ организации «новой комбинации», следовательно, его риск максимален. Предприниматель также способен использовать методику практической минимизации риска, именуемую «риск - менеджмент». Ее механика подобна динамике интерпретации. При интерпретации каждый последующий субъект передачи информации искажает ее. После успешной реализации предпринимателем его новации, и получения предпринимательской прибыли. Появляются предприниматели интерпретаторы, они вняли внешнюю сущность новации, исходя из этого, реализовали «новую комбинацию», опять же с некоторым неопределенным риском, и возможно получили положительный результат, но уже в меньшем размере. Предпринимательская новация внедряется и становится бизнесом,

\footnotetext{
${ }^{3}$ Шумпетер Й.А. Теория экономического развития. М.: Директмедиа Паблишинг. 2008. С. 174.

${ }^{4}$ разум (лат.)
} 
а методиками «риск - менеджмента» происходит минимизация рисков.

Столь распространенный курс подготовки «Master of Business Administration» подразумевает как раз воспитание предпринимателей - интерпретаторов, бизнесменов, способных извлечь рациональные зерна из информационной оболочки общества и при должном обосновании их плодотворности инвесторам воплощать в реальность их «интерпретированные комбинации».

\section{Определение понятия риск}

Исходя из опыта, мы можем моделировать в сознании развитие событий, а по истечении времени сравнивать смоделированную и действительную ситуации. Риск при подобном моделировании имеет значение, если наблюдаемый развитие ситуации также является ее активным участником. Участнику присущ интерес, учет которого находится в прямой зависимости от развития ситуации. Риском является вероятность наступления неблагоприятной для участника ситуации, при которой его интерес будет ущемлен, он понесет урон. Таким образом, риску, как явлению присущи следующие элементы:

- спонтанно развивающаяся ситуация, отчасти подчиненная воли субъекта;

- $\quad$ заинтересованный активный участник ситуации;

- соизмеримость величины возможного урона и вероятности определенного развития событий.

Предприниматель, внедряя свою инновацию, ожидает успеха, ввиду того, что его «новая комбинация» не имела определенного практического выражения, иного ожидать он не может, потому, как его активные действия расценивались бы как прямой урон, в них бы не присутствовало риска, а была бы заведомая неблагоприятная ситуация.
Предприниматель - интерпретатор обладает в сознании потенциально возможной ситуацией - результатом прошлого опыта, своего или предпринимателя, иначе его внимание не было бы обращено на данную комбинацию, потому коридор вероятности наступления неблагоприятной ситуации сужается. Подобно правовой норме организованное «дело» регламентируется и постепенно укладывается в совокупность инструкций, соблюдение которых гарантирует успех и, в конце концов, превращается в «franchising» ${ }^{1}$. В ее рамках бизнесмен банально использует факторы производства по готовой формуле (комбинации) осуществляет операции с умеренным предпринимательским риском. В данной ситуации актуален транзакционный риск. Именно в данной деятельности экономически активному субъекту крайне необходима подготовка, получаемая при освоении курса «МВА», business administration ${ }^{2}$ подразумевает действие в рамках, то ли правового коридора законодательства, то ли корпоративных регламентов и инструкций. Предприниматель же в большей степени личность творческая нежели исполнитель, ему присуща свобода инновации, и радикальные решения, от того и действие принципа «палки» на концах которой расположены предпринимательская прибыль и предпринимательский риск.

\section{Внутренняя сущность предпринимательского риска}

Предпринимательская идея перед реализацией, прежде всего, претендует на часть существующих общественных благ и не может воплотиться без участия капитала. При учете

\footnotetext{
${ }^{1}$ Stephen Spinelli. Franchising: Pathway to Wealth Creation. FT Press. 2004 P. 2.

2 ведение дел, управление делами (англ.)
} 


\section{Тренды и управление - №3(3) • 2013}

риска самым неблагоприятным развитием событий является потеря капитала и упущенная выгода, ибо иначе капитал был бы использован в другом «деле». Если предприниматель использует не свой капитал, а заимствует его, то полагаю, бесспорно, что риск, связанный с сохранностью и приумножением капитала полностью лежит на капиталисте, при этом предприниматель лишь будет обременен совокупностью обязательств по его компенсации.

Возмещение урона - это процесс, полноценный бизнес, актуальный в современных реалиях, при массовом неисполнении обязательств. Суть предпринимательского риска состоит в репутации предпринимателя, интеллектуал, к идеям которого прислушиваются, в процессе своей деловой активности приобрел некий авторитет, проявив свой потенциал. Неудачная новация может лишить предпринимателя внимания инвесторов, и ему придется финансировать свои начала из собственных источников, либо уменьшать собственную часть потенциальной предпринимательской прибыли. Однако причина предпринимательской неудачи находится в любой общественной сфере, состоит не только в ошибке предпринимателя, потому то и идет речь о риске, неопределенности стечения обстоятельств. Анализ поведения главных субъектов экономики - предпринимателей показывает, что кризисные спады в экономике - это результат, прежде всего «неправильных» предпринимательских решений. Причем эти решения неправильные не с точки зрения отдельных предпринимателей, а с точки зрения всего общества. Как правило, эта «неправильность» проявляется на стадии подъема ${ }^{1}$. После активизации деятельности по реализации многих инициа-

${ }^{1}$ Седов В. В. Экономическая теория. Челябинск.: Челяб. гос. ун-т. 2002. С. 79. тив, когда капиталисты предоставили свой капитал предпринимателю и ожидают его возврата с приростом. Предприниматели находятся в центре внимания, ощущают себя хозяевами положения, но прежде всего, являются обязанными должниками, которые удовлетворяют потребности общества. Риск предпринимателей заключается в определении актуальности общественных потребностей, удовлетворение которых обеспечивает «новая комбинация».

\section{Обоснование необходимости защиты предпринимательского риска}

Предпринимательство является катализатором экономической активности и развития в целом. Как фактор производства любое «дело» начинается с предпринимательской инициативы. Потенциал предпринимателя подобно движению информации передается «делу» от него предпринимателям - интерпретаторам и пока остается актуальным оказывает плодотворное влияния. Если в экономической сфере будут действовать только бизнесмены, то со временем все их предприятия, «дела» утратят свой потенциал и будут обычным кругооборотом с минимальным риском и прибылью, в конце концов, и вообще дотационными предприятиями. Предпринимательство способствует движению вперед, раскручивает экономический маховик, но, безусловно, взимает за это плату — часть предпринимательской прибыли, иные доли идут капиталисту и иным субъектам. Предпринимательский риск высок, что может стать препятствием к реализации предпринимательской инициативы. Малая часть предпринимателей обладает капиталом, который может использовать для финансирования своей инновационной деятельности, а профинансировав однажды, при неудаче попросту лишится его и утратит подобную возможность для будущих идей. Рациональным было бы, 
ввиду претензий в отношении предпринимательской прибыли со стороны капиталистов и общества привлечь и страховщиков. То есть для внедрения инновации предпринимателю необходим капитал, а также некоторая дополнительная часть данного капитала, которая взимается со всех предпринимателей. Таким образом, если часть предпринимательских инициатив окажутся провальными, капиталисты получат возмещение своего капитала, а предприниматели, эмоционально реабилитировавшись, продолжат генерацию «новых комбинаций».

Данный механизм не нов, в профессиональной сфере аудиторов, оценщиков, арбитражных управляющих функционирует его интерпретация. Прежде чем приступить к деятельности лицо должно застраховать свою ответственность на некоторую императивно установленную сумму, а в процессе профессионального оказания услуг, по мере необходимости осуществляет дополнительное страхование, если оцениваемый размер обязательств и рисков возрастает. В данном случае речь идет о профессионалах конкретной сферы деятельности, бизнесменах в большей степени, нежели предпринимателях, однако механизм предоставляет практический пример.

\section{Заключение}

Неопределенность развития событий и отсутствие возможности их контроля, а при его наличии фактор стечения обстоятельств обуславливают существование предпринимательского риска, для новаторов экономической активности. Характеризуется он сочетанием возможности достижения как нежелательных, так и особо благоприятных отклонений от запланированных результатов ${ }^{1}$.

\footnotetext{
1 Тэпман Л.Н. Риски в экономике.- М.: ЮНИТИДАНА. 2002. С 11.
}

«Новая комбинация» сочетания факторов производства по задумке предпринимателя сулит ему предпринимательскую прибыль, однако на ином конце «палки» его деятельности находится урон, который не только поглотит заимствованный капитал, но и потенциальное внимание будущих инвесторов. При реализации предпринимательской идеи рационально использовать заимствованный капитал, таким образом, предприниматель переложит на капиталиста часть собственного риска, и станет должником, однако данный статус естественен. Предприниматель для воплощения «новой комбинации» заимствует у общества, прежде всего, денежный капитал, на который приобретаются элементы комбинации. Именно в этот момент предприниматель самостоятельно реализует свои решения и влияет на материализацию риска. Риск представляет неопределенность развития ситуации для ее заинтересованного участника.

Мысль Й. А. Шумпетера, о том, что субъект экономической деятельности в процессе ее осуществления выступает то в роли предпринимателя, то в роли бизнесмена отражает действительную ситуацию. Предприниматель, не имеющий капитала для реализации своих идей, ведет переговоры с бизнесменами, те в свою очередь, предчувствуя упадок своего дела, ищут творческих советников. Но каждый из них внимает только компетентному собеседнику и оппоненту, а критерием всему практика. Потому как для предпринимателя, в узком смысле слова, так и для бизнесмена, в широком смысле слова, важно мнение окружающих о нем, о его действиях, так как именно благоприятное общественное мнение служит источником внимания к новаторским началам предпринимателя. Иначе обстоит дело с бизнесменом, но это предмет иного исследования. 


\section{Библиография}

1. Седов В. В. Экономическая теория. Челябинск.: Челяб. гос. ун-т. 2002.-115 с.

2. Спиркин А. Г. Философия.- М.: Гардарики.-2006.- 736 с.

3. Тэпман Л.Н. Риски в экономике.- М.: ЮНИТИ-ДАНА. 2002.- 380 с.

4. Шумпетер Й. А. Теория экономического развития. М.: Директмедиа Паблишинг. 2008. - $401 \mathrm{c}$.

5. Schumpeter J. A. Theorie der wirtschaftlichen Entwicklung. Siebentes Kapitel. Das Gesamtbild der Volkswirtschaft. Leipzig.: Duncker \& Humblot. 1912.- 56 p.

6. Stephen Spinelli. Franchising: Pathway to Wealth Creation. FT Press. 2004._- 256 p.

\section{References (transliterated)}

1. Sedov V. V. Ekonomicheskaya teoriya. Chelyabinsk.: Chelyab. gos. un-t. 2002.-115 c.

2. Spirkin A.G. Filosofiya.- M.: Gardariki.2006. - $736 \mathrm{c}$.

3. Tepman L. N. Riski v ekonomike.- M.: YuNITI-DANA. 2002.-380 s.

4. Shumpeter I. A. Teoriya ekonomicheskogo razvitiya. M.: Direktmedia Pablishing. 2008.- $401 \mathrm{c}$.

5. Schumpeter J. A. Theorie der wirtschaftlichen Entwicklung. Siebentes Kapitel. Das Gesamtbild der Volkswirtschaft. Leipzig.: Duncker \& Humblot. 1912. - 56 p.

6. Stephen Spinelli. Franchising: Pathway to Wealth Creation. FT Press. 2004.— 256 p. 